\title{
Evaluation of Thyroid Function in Obese Adults with Non-Alcoholic Fatty Liver Disease Attending Tanta University Hospital
}

\author{
ASMAA M. EMARA, M.S.Ch.*; YASSER M. HAFEZ, M.D.*; HOSSAM A. HOUDIB, M.D.**; \\ LOAI M. ELAHWAL, M.D.* and FOUAD Kh. HARRAS, M.D.* \\ The Departments of Internal Medicine* and Clinical Pathology**, Faculty of Medicine, Tanta University
}

\begin{abstract}
Background: Non-Alcoholic Fatty Liver Disease (NAFLD) is considered, most common cause of end stage Liver disorder needing liver transplantation worldwide. NAFLD is considered the hepatic presentation of metabolic syndrome. The association between thyroid dysfunction and NAFLD has increasingly become a focus of research.

Aim of Study: Evaluation of thyroid function in obese adults with non-alcoholic fatty liver disease attending at Tanta University Hospitals from July 2017 to February 2018.

Patients and Method: In our study patients were classified into 2 groups first included 60 obese with Non-Alcoholic Fatty Liver (NAFLD) patients, second group included 60 obese non NAFLD patients recruited from endocrinology, diabetology and metabolism outpatient clinics and inpatient wards, Internal Medicine Department at Tanta University Hospitals. Serum Thyroid Stimulating Hormone (TSH), Free Thyroxine (FT4), Free Tri-iodiothyronine (FT3) by ELISA, Anti thyroid peroxidase (ANTI-TPO), Anti thyroglobulin (Tg $\mathrm{Ab}$ ) and thyroid ultrasound were done for both groups for evaluation of thyroid function in obese adults with nonalcoholic fatty liver disease attending at Tanta University Hospitals from July 2017 to February 2018.
\end{abstract}

Results: TSH levels showed statistically significant difference being higher within obese NAFLD group $p=0.001$ with mean values $2.72 \pm 0.77$ in obese NAFLD group, $1.93 \pm$ 0.66 in obese non-NAFLD group. Also FT4 levels showed statistically significant difference lower in obese NAFLD group $p=0.006$ with mean values $1.08 \pm 0.22$ in obese NAFLD group, $1.25 \pm 0.42$ in obese non-NAFLD group. As regard FT3 levels, ANTI-TPO levels, Tg Ab levels and thyroid ultrasound characters did not show statistically significant difference between the two groups.

Conclusion: We concluded that there was elevation in levels of TSH within the normal range in obese NAFLD group over obese non-NAFLD group. Also FT4 results was within normal range $0.8-1.8 \mathrm{ng} / \mathrm{dl}$ with lower levels in obese NAFLD group than obese non-NAFLD we still need further research on large scale.

Correspondence to: Dr. Asmaa M. Emara, The Department of Internal Medicine, Faculty of Medicine, Tanta University
Key Words: Non-alcoholic fatty liver - Obesity - Thyroid dysfunction.

\section{Introduction}

OBESITY is considered a worldwide health problem and its prevalence is known to increase steadily and dramatically all over the world. In parallel with epidemic obesity, Non-Alcoholic Fatty Liver Disease (NAFLD) has also been increasingly recognized worldwide in the last decade [1]

High Body Mass Index (BMI) is associated with the development of cardiovascular risk factors such as Hypertension (HTN), dyslipidemia, insulin resistance, and Diabetes Mellitus (DM) [2] .

NAFLD is a rapidly growing diagnosis, and it is the most common cause of abnormal liver function tests worldwide [3]. The growing pattern of NAFLD prevalence is generally attributed to a global increase in the prevalence of obesity and other metabolic risk factors [4].

NAFLD encompasses a histological spectrum from isolated hepatic steatosis to steatosis with inflammation, cell injury and possible fibrosis. Some cases may progress to cirrhosis, portal hypertension and consequently, to liver-related death in early adulthood [5]

As the development of NAFLD and NASH (non-alcoholic steatohepatitis) may play a major role in determining the risk for type 2 diabetes and associated metabolic disease, there has been considerable scientific interest in identifying potential risk factors and surrogate markers for NAFLD in recent years [6].

Thyroid hormone status is a key regulator of energy metabolism, while adverse alterations of 
body composition, lipid status, cardiac function/ blood pressure and various nontraditional cardiovascular risk factors are associated with various degrees of thyroid dysfunction, ranging from subclinical to overt hypothyroidism [7]

Elevated levels of Thyroid Stimulating Hormone (TSH) are a common finding in populations of obese adolescents [8]. At present, it remains less clear as to whether the frequently observed increase in TSH level is a secondary consequence of obesity or whether it has an independent role in the pathogenesis of obesity, dyslipidemia and insulin resistance [8].

The studies were conflicting about the association between thyroid abnormalities and NAFLD. Although thyroid dysfunction mainly in the form of hypothyroidism and subclinical hypothyroidism has been reported in NAFLD, other studies did not show any significant correlation between hypothyroidism, and thyroid autoimmunity and NAFLD. However, the latter issue is relatively a new area of investigation that requires much more studies.

\section{Patients and Methods}

\section{Patients of the study:}

The present study included obese with NonAlcoholic Fatty Liver (NAFLD) patients and patients obese without NAFLD recruited from endocrinology, diabetes and metabolism outpatient clinics and inpatient wards, Internal Medicine Department in Tanta University Hospitals and the other 60 were obese non NAFLD from July 2017 to February 2018 (six months period). Obesity was confirmed as BMI was more than $30 \mathrm{~kg} / \mathrm{m}^{2}$.

Study design: Cross sectional study.

\section{Inclusion criteria:}

Patients included in the obese groups were:

Obese patients with BMI more than 30 with NAFLD with three degrees of obesity (mild, moderate and severe) were established on the basis of BMI cut-off points of 30-34.9, 35-39.9 and more than $40 \mathrm{~kg} / \mathrm{m}^{2}$, respectively, from both gender (malefemale) and patients with non-alcoholic liver disease.

\section{Exclusion criteria:}

Patients with hypothyroidism or hyperthyroidism, patients receiving any anti thyroid drugs or thyroid hormones, diabetic patients, patients with alcohol consumption, pregnancy and breast feeding, patients with chronic kidney and liver disease (viral (A-C-B-E), autoimmune, inherited and drug induced), patients with surgeries that lead to secondary NAFLD as gastropexy, small bowel resection, jejunal bypass and biliopancreatic diversion, patients taking any drugs that affect liver and thyroid function as corticosteroid, valproate, amiodarone, autoimmune hepatitis or inherited liver disease as alpha-one antitrypsin deficiency, Wilson disease and hemochromatosis and females taking contraceptive pills or using hormonal IUDs.

Study approval: Permission obtained from the Research Ethics Committee as a part of the Quality Assurance Unit in the Faculty of Medicine Tanta University. An informed written consent was obtained from all participants in this research.

Study design:

Our study patients were classified into 2 groups:

- Group 1: Includes 60 obese with Non-Alcoholic Fatty Liver (NAFLD) patients.

- Group 2: Includes 60 obese non NAFLD patients.

All patients included in this study were subjected to: Through history taking, complete physical examination, measurement of BMI, waist circumference, hip circumference and $\mathrm{W} / \mathrm{H}$ ratio.

\section{Blood sampling and laboratory investigation:}

Blood samples obtained for routine laboratory investigation like Serum total cholesterol, HighDensity Lipoprotein Cholesterol (HDL-C), LowDensity Lipoprotein Cholesterol (LDL-C) and Triglycerides (TG), Serum alanine aminotransferase (ALT), aspartate aminotransferase (AST), yGlutamyl Transferase (GGT), serum albumin, complete blood count, fasting blood glucose level, fasting insulin level for (HOMA-IR) and virology (HBVs Ag, HCV Ab).

Also specific laboratory investigations were done like serum Thyroid Stimulating Hormone (TSH), Free thyroxin (FT4), Free Tri-iodiothyronine (FT3) by ELISA, Anti thyroid peroxidase (ANTITPO) and Anti thyroglobulin (Tg Ab).

\section{Radiological investigations:}

Abdominal ultrasound to detect fatty liver, Thyroid ultrasound is typically used to analyze the appearance of thyroid nodules according to the British Thyroid Association and determine if thyroid nodules are benign or have features that require biopsy were both done for all our patients.

\section{NAFLD fibrosis score:}

NAFLD fibrosis score is based on six readily available variables (i.e. age, Body Mass Index (BMI), hyperglycemia, platelet count, albumin, 
and AST: ALT ratio) and is recognized as a clinically useful tool to identify NAFLD patients with a higher likelihood of having bridging fibrosis and/or cirrhosis was done for all our patients.

\section{Statistical analysis:}

The quantitative variables were presented as a mean \pm Standard Deviation (SD) and compared by $t$-test in case those variables are normally distributed and by Mann-Whitney U-test in case that they are not normally distributed. The categorical variables were statistically analyzed by the chisquare test. SPSS 25.0 software was used for analysis and $p$-values equal to or less than 0.05 were considered significant.

\section{Results}

Regarding gender characters of study participants showed that, the female represented the majority of participants by $69.2 \%$ with more prevalent in NAFLD female group by $75 \%$ than nonNAFLD $63.3 \%$ with $p$-value $=0.166$. There is no age specification between obese NAFLD and obese non-NAFLD groups as mean are (49.70 \pm 4.12$)$, $(48.90 \pm 7.40)$ respectively in the two groups with $p=0.466$ as shown in (Table 1 ).

Table (1): Demographic data age and gender characters of obese NAFLD and non-NAFLD patients.

\begin{tabular}{|c|c|c|c|}
\hline $\begin{array}{l}\text { Age (years): } \\
\text { NAFLD } \\
\text { Non NAFLD }\end{array}$ & $\begin{array}{l}35-58 \\
20-67\end{array}$ & $\begin{array}{l}49.70 \pm 4.12 \\
48.90 \pm 7.40\end{array}$ & 0.466 \\
\hline Gender & NAFLD & Non NAFLD & Total \\
\hline $\begin{array}{c}\text { Male: } \\
\quad \mathrm{N} \\
\%\end{array}$ & $\begin{array}{l}15 \\
25.0 \%\end{array}$ & $\begin{array}{l}22 \\
36.7 \%\end{array}$ & $\begin{array}{l}37 \\
30.8 \%\end{array}$ \\
\hline $\begin{array}{l}\text { Female: } \\
\text { N } \\
\%\end{array}$ & $\begin{array}{l}45 \\
75.0 \%\end{array}$ & $\begin{array}{l}38 \\
63.3 \%\end{array}$ & $\begin{array}{l}83 \\
69.2 \%\end{array}$ \\
\hline $\begin{array}{c}\text { Total: } \\
\mathrm{N} \\
\%\end{array}$ & $\begin{array}{l}60 \\
100.0 \%\end{array}$ & $\begin{array}{l}60 \\
100.0 \%\end{array}$ & $\begin{array}{l}120 \\
100.0 \%\end{array}$ \\
\hline $\begin{array}{c}\text { Chi-square: } \\
\chi^{2} \\
p \text {-value }\end{array}$ & & $\begin{array}{l}1.915 \\
0.166\end{array}$ & \\
\hline
\end{tabular}

Results of (Table 2) revealed that, BMI results of studied participants show that the mean of BMI in obese participants NAFLD is $36.37 \pm 3.44$ and $35.15 \pm 3.21$ for obese participants non-NAFLD with statistically significant results in between both being higher in NAFLD group ( $\left.p=0.048^{*}\right)$. WC results of studied participants show that the mean of WC in obese participants NAFLD is $121.38 \pm 8.70$ and $119.65 \pm 6.74$ for obese participants non -NAFLD with statistically no significant results in between both $(p=0.225)$. There is no significant difference between both groups regard $\mathrm{W} / \mathrm{H}$ ratio $(p=0.104)$, mean of $\mathrm{W} / \mathrm{H}$ ratio of both groups obese NAFLD and obese non-NAFLD $(0.95 \pm 0.06 \mathrm{~cm}$ and $0.93 \pm 0.05 \mathrm{~cm}$ respectively).

As regard ALT, there is significant difference between obese NAFLD and obese non-NAFLD with mean values $29.12 \pm 11.10,21.40 \pm 6.20$ respectively $(p=0.001)$ higher in NAFLD group. Also AST results showed significant difference in both groups ( $p=0.001)$ with mean values in obese NAFLD group $30.72 \pm 11.78$ and $22.85 \pm 6.55$ for obese non-NAFLD group.

Additionally results of (Table 2) showed that fasting glucose results showed no significant difference between two groups $(p=0.235)$ with mean values $123.32 \pm 44.81,113.38 \pm 46.43$ for obese NAFLD and obese non-NAFLD groups respectively. Fasting insulin results of studied participants show that the mean of fasting insulin in obese NAFLD $13.53 \pm 6.32,11.30 \pm 5.85$ for obese nonNAFLD group with significant results difference ( $p=0.047)$ between two groups. Also HOMA IR show statistically significant results in between both being higher in obese NAFLD group by mean $3.80 \pm 1.87$ and mean $2.94 \pm 1.56$ in obese nonNAFLD group $(p=0.007)$.

However, TC results show no significant difference between both groups with mean values $231.80 \pm 45.93$ in obese NAFLD, and 215.68 \pm 50.96 in obese non-NAFLD. While regarding TG results show statistically significant difference higher in obese NAFLD group $p=0.010$ with mean values $225.28 \pm 92.07$ in obese NAFLD group, $190.82 \pm$ 44.74 in obese non-NAFLD group. Also HDL-C results show statistically significant difference higher in obese NAFLD group $p=0.001$ with mean values $37.58 \pm 9.56,50.43 \pm 11.07$ in obese nonNAFLD group. LDL-C results of studied participants show that the mean values in obese participants NAFLD $130.59 \pm 29.86,100.38 \pm 21.25$ in obese non-NAFLD group with statistically significant results in between both being higher in NAFLD group $p=0.001$.

Both platelet count and serum albumin level results show statistically no significant difference between obese NAFLD group and obese nonNAFLD with mean values $(255.55 \pm 67.78,256.83 \pm$ 73.57), (4.00 $\pm 0.49,4.14 \pm 0.58)$ respectively.

Regarding HOMA IR characters of study participants showed in NAFLD group normal, moderate and severe degree of insulin resistance represent $41.7 \%, 40.0 \%, 18.3 \%$ respectively and in non-NAFLD group $58.3 \%, 33.3 \%, 8.3 \%$ for nor- 
mal, moderate and severe degree respectively as presented in (Table 3 ).

Table (2): Laboratory data of the studied groups obese NAFLD and obese non-NAFLD.

\begin{tabular}{|c|c|c|c|c|}
\hline & Range & Mean \pm S.D & $t$.test & $p$.value \\
\hline \multicolumn{5}{|l|}{$B M I(K g / m 2):$} \\
\hline NAFLD & $30.5-45.5$ & $36.37 \pm 3.44$ & \multirow[t]{2}{*}{4.004} & \multirow[t]{2}{*}{$0.048 *$} \\
\hline Non NAFLD & $30.1-41.6$ & $35.15 \pm 3.21$ & & \\
\hline \multicolumn{5}{|l|}{$W C(\mathrm{~cm}):$} \\
\hline NAFLD & $96-137$ & $121.38 \pm 8.70$ & \multirow[t]{2}{*}{1.487} & \multirow[t]{2}{*}{0.225} \\
\hline Non NAFLD & $100-130$ & $119.65 \pm 6.74$ & & \\
\hline \multicolumn{5}{|l|}{ W/H ratio: } \\
\hline NAFLD & $0.81-1.03$ & $0.95 \pm 0.06$ & \multirow[t]{2}{*}{2.677} & \multirow[t]{2}{*}{0.104} \\
\hline Non NAFLD & $0.80-1.01$ & $0.93 \pm 0.05$ & & \\
\hline \multicolumn{5}{|l|}{$A L T(I U / L):$} \\
\hline NAFLD & $10-50$ & $29.12 \pm 11.10$ & \multirow[t]{2}{*}{22.118} & \multirow[t]{2}{*}{$0.001 *$} \\
\hline Non NAFLD & $10-34$ & $21.40 \pm 6.20$ & & \\
\hline \multicolumn{5}{|l|}{$A S T$ (IU/L): } \\
\hline NAFLD & $12-55$ & $30.72 \pm 11.78$ & \multirow[t]{2}{*}{20.440} & \multirow[t]{2}{*}{$0.001 *$} \\
\hline Non NAFLD & $10-37$ & $22.85 \pm 6.55$ & & \\
\hline \multicolumn{5}{|l|}{$G G T(I U / L):$} \\
\hline NAFLD & $11-28$ & $21.57 \pm 5.33$ & \multirow{2}{*}{\multicolumn{2}{|c|}{2.1360 .147}} \\
\hline Non NAFLD & $9-30$ & $20.08 \pm 5.78$ & & \\
\hline \multicolumn{5}{|c|}{ Fasting Glucose ( $\mathrm{mg} / \mathrm{dl})$ : } \\
\hline NAFLD & $78-260$ & $123.57 \pm 44.88$ & \multirow{2}{*}{\multicolumn{2}{|c|}{1.4220 .235}} \\
\hline Non NAFLD & $70-255$ & $113.38 \pm 46.43$ & & \\
\hline Fasting Insulin & & & & \\
\hline NAFLD & $2.8-27.6$ & $13.53 \pm 6.32$ & 4.021 & $0.047 *$ \\
\hline Non NAFLD & $2.6-26$ & $11.30 \pm 5.85$ & & \\
\hline HOMA IR: & & & & \\
\hline NAFLD & $0.57-8.5$ & $3.80 \pm 1.87$ & 7.525 & $0.007 *$ \\
\hline Non NAFLD & $0.46-7.9$ & $2.94 \pm 1.56$ & & \\
\hline$T C(\mathrm{mg} / \mathrm{dl})$ : & & & & \\
\hline NAFLD & $140-330$ & $231.80 \pm 45.93$ & 3.311 & 0.071 \\
\hline Non NAFLD & $120-310$ & $215.68 \pm 50.96$ & & \\
\hline$T G(m g / d l):$ & & & & \\
\hline NAFLD & $100-450$ & $225.28 \pm 92.07$ & 6.802 & $0.010 *$ \\
\hline Non NAFLD & $110-300$ & $190.82 \pm 44.74$ & & \\
\hline$H D L-C(m g / d l):$ & & & & \\
\hline NAFLD & $20-55$ & $37.58 \pm 9.56$ & 46.284 & $0.001 *$ \\
\hline Non NAFLD & $30-78$ & $50.43 \pm 11.07$ & & \\
\hline$L D L-C(m g / d l):$ & & & & \\
\hline NAFLD & $80-195$ & $130.59 \pm 29.86$ & 40.747 & $0.001 *$ \\
\hline Non NAFLD & $65-160$ & $100.38 \pm 21.25$ & & \\
\hline$P L T(X 1000 / \mathrm{cmm}$ & & & & \\
\hline NAFLD & $155-410$ & $255.55 \pm 67.78$ & 0.010 & 0.921 \\
\hline Non NAFLD & $150-400$ & $256.83 \pm 73.57$ & & \\
\hline S. Albumin $(\mathrm{mg} / \mathrm{c}$ & & & & \\
\hline NAFLD & $3.2-5.5$ & $4.00 \pm 0.49$ & 1.486 & 0.225 \\
\hline Non NAFLD & $3-5.2$ & $4.12 \pm 0.53$ & & \\
\hline SD : Standard I & & ALT : Alani & Transam & ninase. \\
\hline BMI : Body Mas & & AST : Aspartat & e Transa & aminase. \\
\hline WC : Waist Circ & & GGT : $\gamma$-Glutan & lyl Trans & sferase. \\
\hline HC : Hip Circu & & FBG : Fasting $\mathrm{I}$ & 3lood G1 & lucose. \\
\hline TG : Triglyceri & & TC : Total Ch & olesterol & \\
\hline $\mathrm{W} / \mathrm{H}$ ratio : Wai & Ratio. & PLT : Platelet & Count. & \\
\hline HOMA IR : Hae & Metabolic $A$ & Assessment for in & sulin res & sistance. \\
\hline HDL-C $\quad$ : Hig & Lipoprote & ein-Cholesterol. & & \\
\hline LDL-C & Lipoprotei & in-Cholesterol. & & \\
\hline
\end{tabular}

Table (3): HOMA IR characters of NAFLD and non-NAFLD participants.

\begin{tabular}{clll}
\hline & NAFLD & Non NAFLD & Total \\
\hline Normal: & & & \\
$\mathrm{N}$ & 25 & 35 & 60 \\
$\%$ & $41.7 \%$ & $58.3 \%$ & $50.0 \%$ \\
Moderate: & & & \\
$\mathrm{N}$ & 24 & 20 & 44 \\
$\%$ & $40.0 \%$ & $33.3 \%$ & $36.7 \%$ \\
Sever: & & & \\
$\mathrm{N}$ & 11 & 5 & 16 \\
$\%$ & $18.3 \%$ & $8.3 \%$ & $13.3 \%$ \\
Total: & & & \\
$\mathrm{N}$ & 60 & 60 & 120 \\
$\%$ & $100.0 \%$ & $100.0 \%$ & $100.0 \%$ \\
Chi-square: & & & \\
$\chi 2$ & & 4.280 & \\
$p$-value & & 0.118 & \\
\hline
\end{tabular}

As shown in (Table 4); TSH results show statistically significant difference higher in obese NAFLD group $p=0.001$ with mean values $2.72 \pm$ 0.77 in obese NAFLD group, $1.93 \pm 0.66$ in obese non-NAFLD group. Also FT4 results show statistically significant difference lower in obese NAFLD group $p=0.006$ with mean values $1.08 \pm 0.22$ in obese NAFLD group, $1.25 \pm 0.42$ in obese nonNAFLD group. As regard, FT3 results there is statistically no significant difference between two groups with mean values $3.1 \pm 0.65,2.99 \pm 0.62$ spectively in obese NAFLD and obese nonNAFLD group. ANTI-TPO results of studied participants show that the mean values in obese parpants NAFLD 25.82 $\pm 9.63,24.37 \pm 6.69$ in obese non-NAFLD group with statistically no significant results in between both groups $(p=0.211)$. $\mathrm{Tg} \mathrm{AB}$ lts of studied participants show that the mean values in obese participants NAFLD $20.11 \pm 6.90$, $21.67 \pm 7.56$ in obese non-NAFLD group with statistically no significant difference $(p=0.240)$.

Table (4): Thyroid functions of the studied groups obese NAFLD and obese non-NAFLD.

\begin{tabular}{lllll}
\hline$T S H(m I U / L):$ & & & \\
$\quad$ NAFLD & $0.8-5.2$ & $2.72 \pm 0.77$ & 36.101 & $0.001^{*}$ \\
$\quad$ Non NAFLD & $0.8-3.1$ & $1.93 \pm 0.66$ & & \\
FT3 $(\mathrm{pg} / \mathrm{ml}):$ & & & & \\
$\quad$ NAFLD & $2.3-4.3$ & $3.1 \pm 0.62$ & 0.835 & 0.363 \\
$\quad$ Non NAFLD & $2.1-4.4$ & $2.99 \pm 0.60$ & & \\
FT4 $(n g / d l):$ & & & & \\
$\quad$ NAFLD & $0.7-1.8$ & $1.08 \pm 0.22$ & 7.893 & $0.006^{*}$ \\
$\quad$ Non NAFLD & $0.8-2.9$ & $1.25 \pm 0.42$ & & \\
ANTI-TPO $(m I U / L):$ & & & & \\
$\quad$ NAFLD & $15-71.5$ & $26.20 \pm 9.01$ & 1.583 & 0.211 \\
$\quad$ Non NAFLD & $11-37$ & $24.37 \pm 6.69$ & & \\
Tg AB $(m I U / L):$ & & & & \\
$\quad$ NAFLD & $6-36$ & $20.11 \pm 6.90$ & 1.393 & 0.240 \\
$\quad$ Non NAFLD & $6-39$ & $21.67 \pm 7.56$ & & \\
\hline
\end{tabular}

TSH : Thyroid Stimulating Hormone.

ANTI-TPO : Anti Thyroid Peroxidase. FT3: Free Tri-iodiothyronine. $\mathrm{Tg} \mathrm{Ab}:$ Anti thyroglobulin. $\quad$ FT4: Free Thyroxine. 
As regard thyroid ultrasound there is no significant difference between NAFLD and non-NAFLD group as all patients had normal ultrasound except 4 patients in NAFLD group have thyroid nodules as presented in (Table 5).

As shown in (Table 6); BMI and WC were significant positively correlated with TSH ( $p=$ $\left.0.043^{*}, r=0.262\right),\left(p=0.047^{*}, r=0.253\right)$ respectively, WC showed significant negatively correlated with FT4 $(p=0.001 *, r=-0.510)$. In non-NAFLD group were significant positively correlated with TSH $(r=0.534, p=0.001 *),(r=0.379, p=0.003 *)$ respectively and both significant negatively correlated with FT4 $\left(r=-0.298, p=0.048^{*}\right),(r=-0.287, p=$ $\left..0 .026^{*}\right)$ respectively.
Table (5): Thyroid ultrasound characters of NAFLD obese and non-NAFLD obese patients.

\begin{tabular}{|c|c|c|c|}
\hline Thyroid US & NAFLD & Non NAFLD & Total \\
\hline \multicolumn{4}{|c|}{ Thyroid nodule U2: } \\
\hline $\mathrm{N}$ & 4 & 0 & 4 \\
\hline$\%$ & $6.7 \%$ & $.0 \%$ & $3.3 \%$ \\
\hline \multicolumn{4}{|l|}{ Normal U1: } \\
\hline $\mathrm{N}$ & 56 & 60 & 116 \\
\hline$\%$ & $93.3 \%$ & $100.0 \%$ & $96.7 \%$ \\
\hline \multicolumn{4}{|l|}{ Total: } \\
\hline $\mathrm{N}$ & 60 & 60 & 120 \\
\hline$\%$ & $100.0 \%$ & $100.0 \%$ & $100.0 \%$ \\
\hline \multicolumn{4}{|l|}{ Chi-square: } \\
\hline$x^{2}$ & & 2.641 & \\
\hline$p$-value & & 0.106 & \\
\hline
\end{tabular}

Table (6): Correlation between BMI, WC and $\mathrm{W} / \mathrm{H}$ and thyroid function in the studied groups.

\begin{tabular}{|c|c|c|c|c|c|c|c|c|}
\hline & \multicolumn{4}{|c|}{ NAFLD } & \multicolumn{4}{|c|}{ Non NAFLD } \\
\hline & \multicolumn{2}{|c|}{ BMI } & \multicolumn{2}{|c|}{ WC } & \multicolumn{2}{|c|}{ BMI } & \multicolumn{2}{|c|}{ WC } \\
\hline & $r$ & $p$ & $r$ & $p$ & $r$ & $p$ & $r$ & $p$ \\
\hline $\mathrm{TSH}$ & 0.262 & $0.043 *$ & 0.253 & $0.047 *$ & 0.379 & $0.003 *$ & 0.534 & $0.001 *$ \\
\hline FT3 & -0.046 & 0.725 & -0.237 & 0.068 & -0.012 & 0.925 & 0.136 & 0.109 \\
\hline FT4 & 0.432 & $0.001^{*}$ & -0.510 & $0.001 *$ & -0.287 & $0.026^{*}$ & -0.298 & $0.048 *$ \\
\hline ANTI-TPO & -0.072 & 0.586 & -0.213 & 0.102 & 0.194 & 0.123 & 0.192 & 0.123 \\
\hline $\operatorname{Tg} \mathrm{AB}$ & 0.184 & 0.159 & 0.476 & $0.001 *$ & -0.147 & 0.263 & -0.112 & 0.393 \\
\hline
\end{tabular}

\section{Discussion}

In parallel with epidemic obesity, NonAlcoholic Fatty Liver Disease (NAFLD) has also been increasingly recognized worldwide in the last decade [9]. Over the past decade, beginning with a study by Liangpunsakul S et al., 2003 [10], the association between thyroid dysfunction and NonAlcoholic Fatty Liver Disease (NAFLD) has increasingly become a focus of research.

Data of the current study demonstrated that there was significant difference between obese NAFLD and obese non-NAFLD group in anthropometric measurement of obesity as significant increase in BMI in NAFLD group than nonNAFLD group. That was in agreement with Giogro $\mathrm{B}$ et al., 2005 that found that BMI is an independent predictor of NAFLD [11].

Also Giogro B et al., 2005, stated that a large waist as identified by the operational definition of the metabolic syndrome, was not an independent predictor of NAFLD in agreement with our study as WC was not elevated in NAFLD obese group over non-NAFLD obese group [11].
Waist circumference is a surrogate marker of visceral adiposity and a risk factor for cardiovascular and metabolic disease [12,13]

Also Qing Pang et al., 2015 stated that high $\mathrm{BMI}$ independently associated with NAFLD, in agreement with our study but also stated that high WC associated with increase in the NAFLD incidence rate against our study [14].

Body mass index and WC have been considered as predictors of NAFLD severity according to Rocha R et al., 2005 [15]. Supporting our data a chinese study Shou-Wu Lee et al., 2016 stated that BMI, and not WC, had a strong positive association with NAFLD. Patients with higher BMI and higher WC had additional risk for NAFLD [16].

Also, there was significant increase in level of ALT, AST in obese NAFLD group than in obese non-NAFLD group and there is no significant difference between the two groups as regard GGT level. This is supported by Dowman JK et al., 2010 that stated that non-alcoholic fatty liver disease is 
the most common cause of elevated liver enzymes (ALT, AST) [17].

By contrast to our study Pouneh M et al., 2003 the entire histologic spectrum of NAFLD can be seen in individuals with normal ALT values [18]

As regard to HOMA IR, we found that it was significantly higher in obese NAFLD group than obese non-NAFLD, similar results were obtained by Adel A et al., 2012 that clarified that HOMAIR was a significant independent predictor of the grade of steatosis and stage of fibrosis [19].

In our study, there was no significant difference in TC levels between obese NAFLD, obese nonNAFLD group. While there is significant increase in the level of TG, LDL-C in obese NAFLD than obese non-NAFLD group, HDL-C levels show significant decrease in NAFLD group than nonNAFLD group.

Our study is supported by Muhammad W et al., 2017 that who stated that dyslipidemia in nonalcoholic fatty liver disease in form of atherogenic dyslipidemia characterized by high LDL-C levels, low HDL-C levels and hypertriglyceridemia [20] Zhang QQ et al., 2015, Chatrath $\mathrm{H}$ et al., 2012, shivaram $\mathrm{P}$ et al., 2017 studies in agreement to our study regard TG, HDL-C, LDL-C [21-23] .

In NAFLD, this intrahepatic lipid accumulation can be explained from lipid metabolism abnormalities such as increased whole body lipolysis, liver Free Fatty Acid (FFA) uptake and Very Low Density Lipoprotein (VLDL) synthesis as well as reduced FFA oxidation and Triglycerides (TG) export [24].

These alterations in lipid metabolism are linked to an induction of inflammation and oxidative stress as well as to abnormal adipokine (such as leptin, adiponectin, resistin, and retinol binding protein-4) production that affect signaling pathways $[25,26]$

In our study, there was significant difference between both obese groups NAFLD, non-NAFLD as regard TSH levels as in NAFLD group there is elevation of TSH within normal range (0.4-4.2mIU /L (milli international units per liter) for adult about 39 patient with NAFLD have TSH level $<2.7 \mathrm{mIU}$ $/ \mathrm{L}$, as compared with obese non-NAFLD group. Only one patient reported subclinical hypothyroidism with TSH level 5.2mIU/L and normal FT3, FT4.

Also FT4 results show statistically significant difference lower within normal range in obese
NAFLD group than obese non-NAFLD group. FT3 results there are no significant difference between two groups. Thyroid function tests were within normal range in all groups.

Our study supported by Jiaoyue Z et al., 2012 study that found high normal value of TSH had relation to obesity and NAFLD and females and males with NAFLD had a significantly higher normal level of TSH than those non-NAFLD [27]

In agreement with our study Carolina $\mathrm{C}$ et al., 2017 stated that the association between TSH levels within the reference range and NAFLD seems to be mediated by metabolic syndrome criteria [28] Also Lucia C et al., 2013 results with our study stated that high-though normal TSH independently predict NASH [29]. The same Moustafa et al., 2009 cleared that serum TSH level in NASH patients was higher than healthy controls $(2.1 \pm 0.75 \mathrm{IU} / \mathrm{mL}$ vs. 1.75 \pm 0.9 U/WL) within normal range [30] .

As regard FT4 as in our study Ulla L et al., 2015 stated a significant inverse association between the FT4 concentration of NAFLD could be demonstrated, while no significant association could be identified for FT3 or TSH [31]

By contrast, the FT3 concentration, both in Ulla L et al., 2015 and in those of Ittermann et al., 2012 and $\mathrm{Xu}$ et al., 2011, had no identified value as a marker for NAFLD as the present study [3133].

In contrast to our data some studies included in Ahad E et al., 2014, reported growing data about higher prevalence of thyroid dysfunction in the form of overt or subclinical hypothyroidism among patients with NAFLD/NASH [34], Like Pagadala et al., 2012 reported that hypothyroidism was more common in patients with NASH compared to patients with NAFLD [35].

Chen Y et al., 2018 achinese study reported that the status of metabolic disorders like obesity and NAFLD might be associated with higher risks of TN in both genders. In women, obesity, central obesity, and NAFLD might contribute to the development of a taller-than-wide thyroid nodule, against with the present study [36]

As regard thyroid antibodies ANTI-TPO and $\mathrm{Tg} \mathrm{Ab}$ there is no significant difference between NAFLD and Non-NAFLD groups. With the present study Eshraghian et al., 2013 reported that no association between thyroid autoimmunity and NAFLD like our study as regard ANTI-TPO and $\mathrm{Tg} \mathrm{Ab}$ [37] 


\section{Conflict of interests:}

The authors declared that there is no conflict of interests.

\section{Acknowledgement:}

No fund was received for this study.

\section{References}

1- TREMMEL M., GERDTHAM U.G., NILSSON P.M., et al.: Economic burden of obesity: A systematic literature review. International Journal of Environmental Research and Public Health, 14 (4): 435, 2017.

2- PICHÉ M.E., POIRIER P., LEMIEUX I., et al.: Overview of Epidemiology and Contribution of Obesity and Body Fat Distribution to Cardiovascular Disease: An Update. Progress in Cardiovascular Diseases, 61 (1): 1-86, 2018.

3- CHALASANI N., YOUNOSSI Z., LAVINE J.E., et al.: The diagnosis and management of nonalcoholic fatty liver disease: Practice guidance from the American Association for the Study of Liver Diseases. Hepatology, 67 (1): 32857, 2018.

4- ALLEN A.M., THERNEAU T.M., LARSON J.J., et al.: Nonalcoholic fatty liver disease incidence and impact on metabolic burden and death: A 20 year-community study. Hepatology, 67 (5): 1726-36, 2018.

5- RINELLA M.E.: Nonalcoholic fatty liver disease: A systematic review. JAMA, 313 (22): 2263-73, 2015.

6- LONARDO A., NASCIMBENI F., TARGHER G., et al.: AISF position paper on nonalcoholic fatty liver disease (NAFLD): Updates and future directions. Digestive and Liver Disease, 49 (5): 471-83, 2017.

7- MULLUR R., LIU Y.Y. and BRENT G.A.: Thyroid hormone regulation of metabolism. Physiological reviews, 94 (2): 355-82, 2014.

8- DAHL M., OHRT J.D., FONVIG C.E., et al.: Subclinical hypothyroidism in Danish lean and obese children and adolescents. Journal of Clinical Research in Pediatric Endocrinology, 9 (1): 8, 2017.

9- VERNON G., BARANOVA A. and YOUNOSSI Z.: Systematic review: The epidemiology and natural history of non-alcoholic fatty liver disease and non-alcoholic steatohepatitis in adults. Alimentary Pharmacology \& Therapeutics, 34 (3): 274-85, 2011.

10-LIANGPUNSAKUL S. and CHALASANI N.: Is hypothyroidism a risk factor for non-alcoholic steatohepatitis? Journal of Clinical Gastroenterology, 37 (4): 340-3, 2003.

11- BEDOGNI G., MIGLIOLI L., MASUTTI F., et al.: Prevalence of and risk factors for nonalcoholic fatty liver disease: The Dionysos nutrition and liver study. Hepatology, 42 (1): 44-52, 2005.

12- KIHARA S. and MATSUZAWA Y.: Fat distribution and cardiovascular disease risk. Current Cardiovascular Risk Reports, 9 (3): 8, 2015.

13- BORRUEL S., MOLTÓ J.F., ALPAÑÉS M., et al.: Surrogate markers of visceral adiposity in young adults: Waist circumference and body mass index are more accurate than waist hip ratio, model of adipose distribution and visceral adiposity index. PloS one, 9 (12): e114112, 2014.
14- PANG Q., ZHANG J.Y., SONG S.D., et al.: Central obesity and nonalcoholic fatty liver disease risk after adjusting for body mass index. World Journal of Gastroenterology: WJG, 21 (5): 1650, 2015.

15- ROCHA R., COTRIM H.P., CARVALHO F., et al.: Body mass index and waist circumference in non-alcoholic fatty liver disease. Journal of Human Nutrition and Dietetics, 18 (5): 365-70, 2005.

16- SHOU-WU LEE, YANG S.S., LEE T.Y., et al.: The association of non-alcoholic fatty liver disease with body mass index and waist circumference in a Chinese population. J. Adv. Nutr. Hum. Metab., 2: e1483, 2016.

17- DOWMAN J.K., TOMLINSON J. and NEWSOME P. Systematic review: The diagnosis and staging of nonalcoholic fatty liver disease and non-alcoholic steatohepatitis. Alimentary Pharmacology \& Therapeutics, 33 (5): 525-40, 2011.

18- POUNEH M., CONTOS M.J., HAQUE M., et al.: Clinical and histologic spectrum of nonalcoholic fatty liver disease associated with normal ALT values. Hepatology, 37 (6): 1286-92, 2003.

19- ADEL A.M., BAKIR A.S. and SHABANA S.S.: Serum TGF- $\beta$, Serum MMP-1, and HOMA-IR as non-invasive predictors of fibrosis in Egyptian patients with NAFLD. Saudi Journal of Gastroenterology: Official Journal of the Saudi Gastroenterology Association, 18 (5): 327 , 2012.

20- MUHAMMED W., SHAH N.U., ACHAKZAI M.S., et al.: Frequency of Dyslipidemia in Non Alcoholic Fatty Liver Disease Patients. Pakistan Journal of Medical \& Health Sciences, 1 (1): 103-11, 2017.

21- ZHANG Q.Q. and LU L.G.: Nonalcoholic fatty liver disease: Dyslipidemia, risk for cardiovascular complications, and treatment strategy. Journal of Clinical and Translational Hepatology, 3 (1): 78, 2015.

22- CHATRATH H., VUPPALANCHI R., CHALASANI N., et al.: Dyslipidemia in patients with nonalcoholic fatty liver disease. Seminars in liver disease, 33 (4): 380-8, 2012.

23- SHIVARAM P., SWAIN M., NATH P., et al.: Prevalence and Risk Factors for Dyslipidemia in Patients With NonAlcoholic Fatty Liver Disease (NAFLD). Journal of Clinical and Experimental Hepatology, 7: S35-S6, 2017.

24- ALMEDA-VALDES P., ALTAMIRANO-BARRERA A. and MÉNDEZ-SÁNCHEZ N.: Insights in non-alcoholic fatty liver disease pathophysiology with lipidomic analyses. Annals of Hepatology, 14 (4): 567-9, 2015.

25- ADOLPH T.E., GRANDER C., GRABHERR F., et al.: Adipokines and non-alcoholic fatty liver disease: Multiple interactions. International Journal of Molecular Sciences, 18 (8): 1649, 2017.

26- POLYZOS S.A., ARONIS K.N., KOUNTOURAS J., et al.: Circulating leptin in non-alcoholic fatty liver disease: A systematic review and meta-analysis. Springer, 59 (1): 30-43, 2016.

27- JIAOYUE Z., SUN H., CHEN L., ZHENG J., HU X., WANG S., et al.: Relationship between serum TSH level with obesity and NAFLD in euthyroid subjects. Journal of Huazhong University of Science and Technology [Medical Sciences], 32 (1): 47-52, 2012. 
28- CAROLINA C., CESENA F.H., TABONE V.A., et al. Association Between TSH Levels and Hepatic Steatosis is Mediated by Metabolic Syndrome Factors. Am. Heart Assoc., 136 (1): 15477, 2017.

29- LUCIA C., BALLESTRI S., LONARDO A., et al.: Is nonalcoholic steatohepatitis associated with a high-thoughnormal thyroid stimulating hormone level and lower cholesterol levels? Internal and Emergency Medicine, 8 (4): 297-305, 2013.

30- MOUSTAFA A.H.A., ALI E.M., MOHAMED T.M., et al.: Oxidative stress and thyroid hormones in patients with liver diseases. European Journal of Internal Medicine, 20 (7): 703-8, 2009.

31- ULLA L., HOLZNER D., DENZER C., OEZTUERK S., et al.: Subclinical and clinical hypothyroidism and nonalcoholic fatty liver disease: A cross-sectional study of a random population sample aged 18 to 65 years. BMC endocrine disorders, 15 (1): 41, 2015.

32- XU C., XU L., YU C., et al.: Association between thyroid function and nonalcoholic fatty liver disease in euthyroid elderly Chinese. Clinical Endocrinology, 75 (2): 240-6, 2011.

33- ITTERMANN T., HARING R., WALLASCHOFSKI H., et al.: Inverse association between serum free thyroxine levels and hepatic steatosis: Results from the Study of Health in Pomerania. Thyroid., 22 (6): 568-74, 2012.

34- AHAD E. and JAHROMI A.H.: Non-alcoholic fatty liver disease and thyroid dysfunction: A systematic review. World Journal of Gastroenterology: WJG, 20 (25): 8102, 2014.

35- PAGADALA M.R., ZEIN C.O., DASARATHY S., et al.: Prevalence of hypothyroidism in nonalcoholic fatty liver disease. Digestive diseases and sciences, 57 (2): 528-34, 2012.

36- CHEN Y., ZHU C., CHEN Y., et al.: The Association of Thyroid Nodules with Metabolic Status: A Cross-Sectional SPECT-China Study, 2018.

37- AHAD ESHRAGHIAN M., ESHRAGHIAN M.D.H., et al.: Nonalcoholic fatty liver disease in a cluster of Iranian popula-tion: Thyroid status and metabolic risk factors. Archives of Iranian Medicine, 16 (10): 584, 2013. 


\section{تقييم وظائف الغدة الدرقية فى البالغين

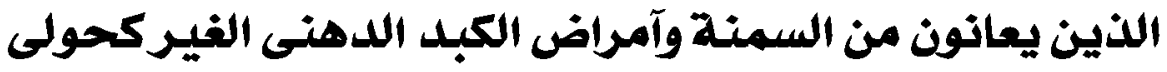 \\ المترددين على مستشفيات جامعة المن طنطا}

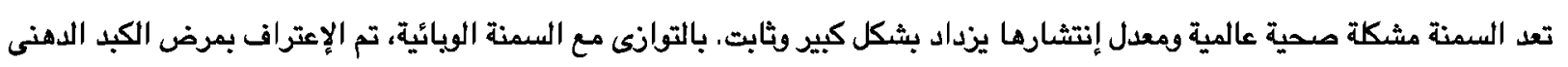
غير الكحلى بشكل متزايد فى جميع آنحاء العالم فى العقد الآخير.

يرتبط إرتقاع مؤشر كتلة الجسم بتطود عوامل الخطر القليية الوعائية مثل إرتفاع ضغط الدم وإرتفاع دهون الدم الضارة ومقاومة الآنسولين وداء السكرى.

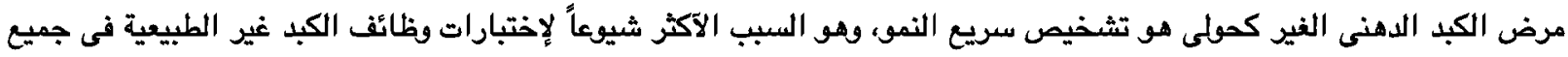

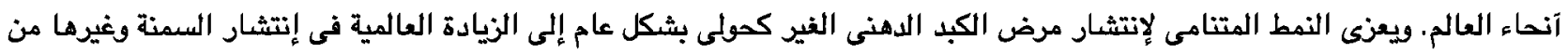
عوامل الخطر الآيضية.

يشمل مرض الكبد الدهنى الغير كحملى طيف نسيجى من تنكس دهنى كبدى معزفل إلى تنكس دهنى مع إلى إلتهاب وإصابة الخلية وتليف

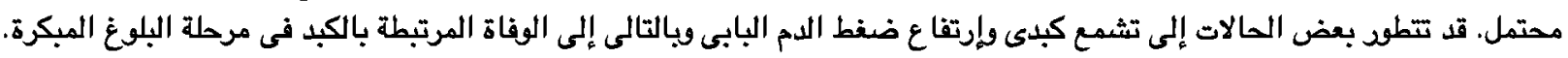

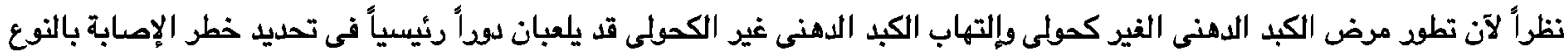

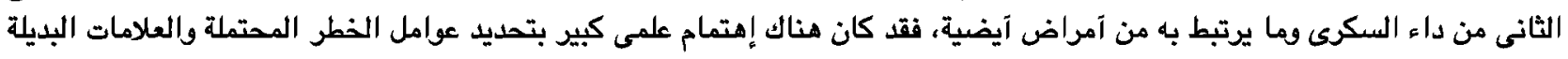

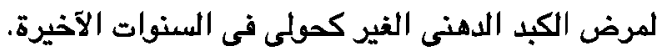

حالة هرمون الغدة الدرقية هو منظم رئيسى لعملية التمثيل الغذائى اللطاقة، فى حين ترتبط التغيرات الضـارة فى تكوين الجسم وحالة الدهون،

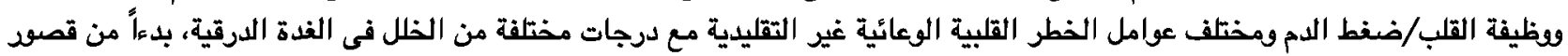
الغدة الدرقية دون الإكلينيكى إلى قصود الغدة الدرقية الواضع.

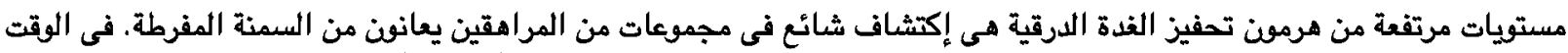

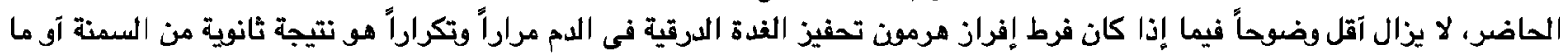

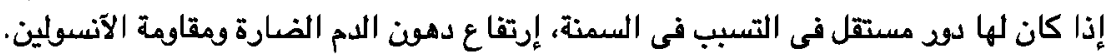

الهدف من البحث: تهدف الدراسة إلى تقييم وظائف الفدة الدرقية فى البالفين الذين يعانون من السمنة ومرض الكئ الكبد الدهنى الفير كصولى

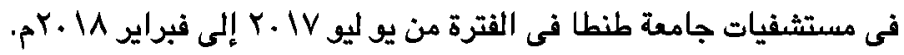

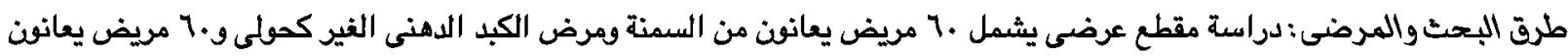

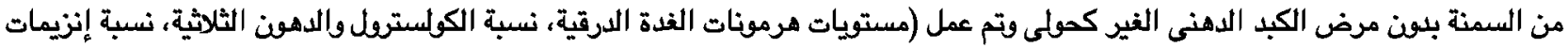

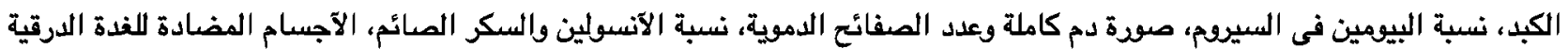

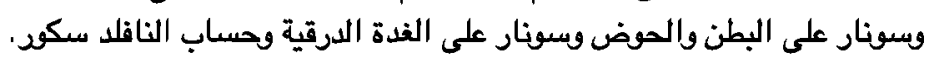

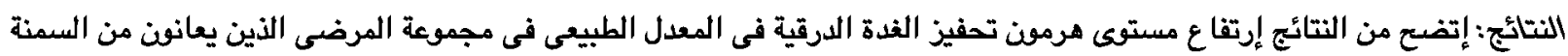

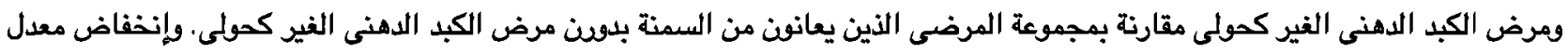

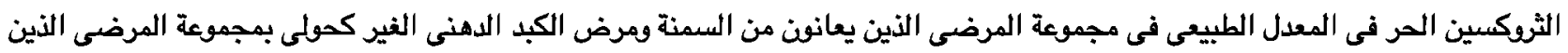
يعانون من السمنة بدن مرض الكبد الدهنى الكنى الغير كحولى.

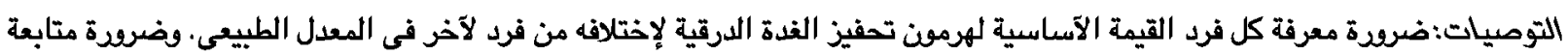

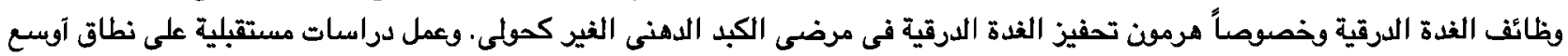

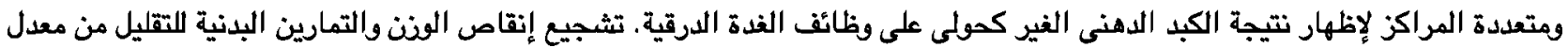

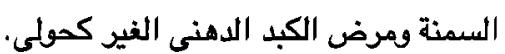

